\title{
Comparison of transvaginal sacrospinous ligament fixation with abdominal sacrocolpopexy in treatment of post-hysterectomy vault prolapse-a prospective randomized study
}

\author{
Kamal Kumar Dash, Anjan Dasgupta*, Abirbhab Pal, Ayantika Chakraborty, \\ Barsarani Dash, Partha Ghosh
}

Department of Gynecology and Obstetrics, Midnapore Medical College, Paschim Medinipur, West Bengal, India

Received: 29 October 2021

Accepted: 26 November 2021

*Correspondence:

Dr. Anjan Dasgupta,

E-mail: dasguptadranjan08@gmail.com

Copyright: () the author(s), publisher and licensee Medip Academy. This is an open-access article distributed under the terms of the Creative Commons Attribution Non-Commercial License, which permits unrestricted non-commercial use, distribution, and reproduction in any medium, provided the original work is properly cited.

\begin{abstract}
Background: Vaginal vault prolapse is a common condition following abdominal or vaginal hysterectomy causing negative impact on women's quality of life. The study compares the efficacy of abdominal and vaginal route surgery in correcting post-hysterectomy vault prolapse by postoperative assessment and at least twelve months follow up.

Methods: A prospective comparative study among post-hysterectomy patients attending the GOPD of Midnapore Medical College diagnosed as vaginal vault prolapse at least stage 2 between January 2013 to December 2019. The study population included 31 women divided into two groups-group A included 16 women underwent unilateral sacrospinous ligament fixation (SSF) and group B included 15 women underwent abdominal sacrocolpopexy (ASC).

Results: There was no significant difference between the two groups in terms of mean age, mean weight, mean parity and BMI, hence both groups are comparable. The mean operating time was $117 \pm 19.68$ min in ASC group and $83.25 \pm 11.28 \mathrm{~min}$ in SSF group ( $\mathrm{p}<0.005)$; significant mean blood loss was reported in ASC group $(373 \pm 97.79 \mathrm{ml}$ in ASC group versus $193.125 \pm 98.97 \mathrm{ml}$ in SSF group, $\mathrm{p}<0.005)$, more hospital stays in ASC group (p<0.005) and more post operative complications in ASC group than SSF group. At follow up, the mean vaginal length showed significantly longer for ASC group than that of SSF group ( $p<0.005)$.

Conclusions: ASC and SSF, both techniques are effective in management of vault prolapse in hands of an expert though recovery time is much quicker in SSF group.
\end{abstract}

Keywords: Vaginal vault prolapse, ASC, SSF, POP-Q

\section{INTRODUCTION}

Vaginal vault prolapse is not an uncommon condition following abdominal or vaginal hysterectomy which has a negative impact on women's quality of life due to associated urinary, anorectal and sexual dysfunction. Vault prolapse has been defined by the international continence society (ICS) as descent of the vaginal cuff below a point that is $2 \mathrm{~cm}$ less than the total vaginal length above the plane of hymen. ${ }^{1}$ The vaginal cuff scar corresponds to point $\mathrm{C}$ on the pelvic organ prolapse quantification (POP-
Q) grid. ${ }^{2}$ It occurs when the upper vagina bulges into or outside the vagina and coexistent pelvic floor defects like cystocele, rectocele or enterocele is present in $72 \%$ of cases either singly or in combination. ${ }^{3}$ Surgery for genital prolapse is one of the most common yet a challenging operation in gynecology as $25 \%$ of these operations are performed for recurrence, suggesting that success rates for initial operations are poor. ${ }^{4}$ The ideal repair procedure for post-hysterectomy vaginal apical support is ill-defined as there is no gold standard assessment technique till date. The traditional approach to treat vaginal vault prolapse by 
performing a pelvic floor repair is not logical, as it neither create a strong apical vaginal support nor preserve the adequate vaginal length. The surgical options for the correction of vault prolapse lie between abdominal and vaginal approach, based on patient's age, co-morbidity, previous surgery and level of physical and sexual activity. ${ }^{5}$ Experience of the surgeon and his preference is also an important factor. To date, more than 40 different surgical procedures to correct vaginal vault prolapse has been reported, but vaginal SSF and abdominal sacrocolpopexy are among the two are more successful and of prime concern. ${ }^{6}$

\section{METHODS}

This was a randomized prospective study undertaken to compare the effectiveness of SSF and ASC over each other in correcting post-hysterectomy vaginal vault prolapse. The study population included post-hysterectomy women attending OPD clinic of the department of $G$ and 0 at Midnapore medical college, West Bengal, India with sign of at least stage 2 vault prolapses between Jan 2013 to December 2019. Those patients who were aged more than 65 years, had pelvic infections or any chronic disabling disease, were excluded from the study. Ethical approval from the institution had undertaken before conducting the study.

All patients were examined thoroughly for pelvic organ prolapse quantification (POP-Q) before inclusion according to the recommendations of ICS and stage 2 and above were selected. Those who have agreed to participate in the study and gave written consent after counseling were included.

A total of 31 patients were allocated randomly to any of the two above mentioned groups, i.e., group A, included 16 patients had unilateral SSF operations and group B included 15 patients had ASC operations. Both the groups were homogeneous in respect to the age, parity, body mass index and staging of vault prolapse.

For SSF, a longitudinal incision was given on the posterior vaginal wall to enter the recto-vaginal space. The epithelium is dissected laterally and pararectal space opened on the right side. The right sacrospinous ligament preferred because retraction of rectum is easier on the opposite side and a right-handed surgeon can approach that side more easily. After dividing the rectal pillar, blunt finger dissection in that space ischial spine is reached as a prominent landmark and three narrow malleable retractors were used for clear visualization. Though Miya's hook makes the placement of suture easy, due to unavailability, we used 12-inch-long slender needle holder. Using proline number 1 suture, two sutures was placed $2 \mathrm{~cm}$ medial to the ischial spine through partial thickness to avoid injury to the neurovascular bundle. Anterior or posterior repair was performed as per requirement after completion of vault fixation.
In ASC, the abdomen entered through low transverse incision. Vaginal vault was elevated by tight vaginal packing just before operation. The peritoneum over the vault was dissected and reflected by scissors to expose the rectovaginal and pubocervical fascia, then extending upwards to the sacral promontory taking care not to injure the presacral vessels, common iliac vessels, ureters and sigmoid colon. The distal end of mesh $(4 \times 14 \mathrm{~cm}$ polypropylene) was attached to the top of the vaginal vault and a part of posterior vaginal wall with 4-6 interrupted full thickness stitches using proline 01 suture excluding the vaginal mucosa and proximal end to the anterior longitudinal ligaments of the sacral promontory, care was taken not to injure underlying vessels or overcorrect the apex of the vagina. Moschowitz procedure was done to obliterate cul-de-sac. A separate small piece of mesh was also placed on the anterior vaginal wall and sewn to the original mesh at the apex; this was done for strengthening the anterior compartment defect where necessary. Peritoneum was closed over the mesh and intraperitoneal drain was given where required. After the end of the procedure, patient was placed in dorsal position, vaginal pack was removed, rectocele was corrected where necessary and overall assessment done after correction.

The outcome measures of both groups that were compared included intraoperative variables like operation time, intraoperative blood loss, and intraoperative complications (like visceral or vascular injury). Post-operative events in the form of duration of hospital stay and immediate postoperative complications were also compared between the groups.

Follow up measures of both the groups were done at the end of 6 months and 12 months by pelvic assessment to look for any persistent prolapse, compartmental defect and position of vaginal apex above the hymenal ring. Sexual function was also assessed by direct questionnaire related with sexual function and dyspareunia and by measuring the length of vagina.

\section{Statistical analysis}

Data was analyzed by using the statistical package for social sciences (SPSS version 25). Numerical data were expressed as means \pm standard deviations. Statistical differences of quantitative variables between the two groups were calculated using unpaired student's t-test and chi-square test for qualitative variables. A $\mathrm{p}$ value was considered significant when it is $<0.05$.

\section{RESULTS}

The demographic and clinical features of the patients of SSF group and ASC group are described in Table 1. There was no significant difference between the two groups in terms of mean age, mean weight, mean parity and BMI (Table 1, p>0.05), hence both groups are comparable though the ages of SSF group were slightly older. There was significant difference in past instrumental delivery 
$(\mathrm{p}<0.05)$ between the groups, 4 instrumental delivery (25\%) had occurred in SSF group whereas 2 cases $(13.33 \%)$ had instrumental delivery in ASC group. Cystocele was present in 6 patients of SSF group but in 3 patients of ASC group ( $\mathrm{p}<0.05)$. A single woman could have more than one symptom; moreover, $68.75 \%$ patients of SSF group and $80 \%$ patients of ASC group were sexually active found on close interview. Operations were performed either by epidural anesthesia $(n=19,61.29 \%)$ or general anesthesia $(n=12,38.71 \%)$.

Perioperative outcomes encountered in vaginal SSF and ASC are summarized in table 2. The mean duration of operation was significantly longer in ASC group compared to SSF group $(\mathrm{p}<0.0005)$. There was significant mean blood loss reported in ASC group $(\mathrm{p}<0.0005)$; concurrent cystocele repair was more in SSF group $(\mathrm{p}<0.005)$ and significantly more vascular or visceral injury found in SSF group $(\mathrm{p}<0.0005)$. Regarding vascular and visceral damage, one patient from abdominal sacrocolpopexy group had internal iliac vein injury with profuse bleeding which was tackled successfully with prolonged mop compression. In SSF group, one patient had bladder injury during anterior repair and one patient had injury of inferior gluteal vein during placement of sacrospinous suture with fair amount of bleeding; both cases were tackled successfully.

Table 1. Demographic-clinical features of patients operated with SSF and ASC.

\begin{tabular}{|c|c|c|c|}
\hline $\begin{array}{l}\text { Different } \\
\text { variables }\end{array}$ & $\begin{array}{l}\text { SSF, } \\
(n=16)\end{array}$ & $\begin{array}{l}\text { ASC, } \\
(n=15)\end{array}$ & P value \\
\hline $\begin{array}{l}\text { Mean age } \\
\text { (years) }\end{array}$ & $\begin{array}{l}57.625 \pm \\
3.77\end{array}$ & $\begin{array}{l}55.733 \pm \\
3.55\end{array}$ & 0.1622 \\
\hline $\begin{array}{l}\text { Mean weight } \\
\text { (kg) }\end{array}$ & $\begin{array}{l}60.375 \pm \\
5.251\end{array}$ & $\begin{array}{l}57.066 \pm \\
5.73\end{array}$ & 0.1044 \\
\hline $\begin{array}{l}\text { Mean parity } \\
\text { (n) }\end{array}$ & $\begin{array}{l}3.625 \pm \\
0.95\end{array}$ & $\begin{array}{l}3.133 \pm \\
0.833\end{array}$ & 0.1392 \\
\hline $\begin{array}{l}\text { Mean BMI } \\
\left(\mathrm{kg} / \mathrm{m}^{2}\right)\end{array}$ & $\begin{array}{l}26.539 \pm \\
2.44\end{array}$ & $\begin{array}{l}24.61 \pm \\
2.879\end{array}$ & 0.058 \\
\hline $\begin{array}{l}\text { Previous } \\
\text { instrumental } \\
\text { delivery }\end{array}$ & 4 & 2 & 0.00013 \\
\hline $\begin{array}{l}\text { Previous } \\
\text { hysterectomy } \\
\text { due to } \\
\text { uterine } \\
\text { prolapse }\end{array}$ & 4 & 2 & 0.149 \\
\hline $\begin{array}{l}\text { Grade } 3 \text { or } 4 \\
\text { vault } \\
\text { prolapse }\end{array}$ & 14 & 11 & 0.17753 \\
\hline $\begin{array}{l}\text { Sexual } \\
\text { activity }\end{array}$ & $\begin{array}{l}11 \\
(68.75 \%)\end{array}$ & $\begin{array}{l}12 \\
(80 \%)\end{array}$ & 0.7831 \\
\hline Cystocele & $\begin{array}{l}6 \\
(37.5 \%)\end{array}$ & $\begin{array}{l}3 \\
(20 \%)\end{array}$ & 0.003857 \\
\hline Rectocele & $\begin{array}{l}5 \\
(31.25 \%)\end{array}$ & $\begin{array}{l}6 \\
(40 \%)\end{array}$ & 0.317311 \\
\hline
\end{tabular}

Table 2: Perioperative events of patients operated with SSF and ASC.

\begin{tabular}{|ll|ll|}
\hline Events & $\begin{array}{l}\text { SSF, } \\
(\mathbf{n = 1 6})\end{array}$ & $\begin{array}{l}\text { ASC, } \\
(\mathbf{n = 1 5})\end{array}$ & P value \\
\hline $\begin{array}{l}\text { Mean duration } \\
\text { of surgery (min) }\end{array}$ & $\begin{array}{l}83.25 \pm \\
11.28\end{array}$ & $\begin{array}{l}117 \pm \\
19.68\end{array}$ & 0.00000206 \\
\hline Mean blood loss & $\begin{array}{l}193.125 \pm \\
98.97\end{array}$ & $\begin{array}{l}373 \pm \\
97.79\end{array}$ & 0.00001997 \\
\hline $\begin{array}{l}\text { Transfusion of } \\
\text { blood }\end{array}$ & 2 & 5 & 0.0651 \\
\hline $\begin{array}{l}\text { Concurrent } \\
\text { cystocele repair }\end{array}$ & 6 & 3 & 0.003857 \\
\hline $\begin{array}{l}\text { Concurrent } \\
\text { rectocele repair }\end{array}$ & 5 & 6 & 0.3173 \\
\hline $\begin{array}{l}\text { Visceral/vascular } \\
\text { injury }\end{array}$ & 2 & 1 & 0.00002263 \\
\hline
\end{tabular}

Table 3 showed immediate postoperative events among the two groups. Overall, postoperative complications encountered more in ASC group than the SSF group. The mean hospital bed occupancy was significantly of longer period in ASC group compare to SSF group $(\mathrm{p}<0.005)$. A significantly larger percentage of women who underwent ASC developed postoperative pyrexia, Hematuria, abdominal distension and wound infections $(\mathrm{p}<0.005)$. Postoperative hematuria was more in abdominal sacrocolpopexy group not due to visceral injury, but due to more vigorous separation of bladder from vaginal vault causing blood-stained urine which resolved spontaneously within 24 hours. Single case of hematuria found in the SSF group was due to bladder injury during anterior repair which was recognized and repaired immediately followed by continuous catheterization for 2 weeks. Three patients of ASC group and one patient of SSF group had abdominal distension due to paralytic ileus which resolved spontaneously on third postoperative day. There was also significant difference of postoperative wound infection between abdominal sacrocolpopexy and SSF group $(\mathrm{p}<0.00005)$.

Table 3: Immediate postoperative complications between SSF and ASC group.

\begin{tabular}{|c|c|c|c|}
\hline $\begin{array}{l}\text { Different } \\
\text { variables }\end{array}$ & $\begin{array}{l}\text { SSF, } \\
(n=16)\end{array}$ & $\begin{array}{l}\mathbf{A S C} \\
(\mathrm{n}=15)\end{array}$ & $P$ value \\
\hline $\begin{array}{l}\text { Mean hospital } \\
\text { stay (days) }\end{array}$ & $\begin{array}{l}5.8 \pm \\
2.73\end{array}$ & $\begin{array}{l}8.187 \pm \\
1.32\end{array}$ & 0.00399 \\
\hline Pyrexia (>37.5 c) & 2 & 8 & 0.0012 \\
\hline $\begin{array}{l}\text { Urinary } \\
\text { symptoms }\end{array}$ & 4 & 1 & 0.0000284 \\
\hline Hematuria & 1 & 4 & 0.0000284 \\
\hline $\begin{array}{l}\text { Abdominal } \\
\text { distension }\end{array}$ & 1 & 3 & 0.00000852 \\
\hline $\begin{array}{l}\text { Mean urinary } \\
\text { catheter } \\
\text { duration (days) }\end{array}$ & $\begin{array}{l}5.867 \pm \\
4.56\end{array}$ & $\begin{array}{l}3.375 \pm \\
0.80\end{array}$ & 0.04009 \\
\hline Wound infection & 1 & 3 & 0.000008523 \\
\hline
\end{tabular}


Table 4 depicts difference of long terms variables between the two groups after 12 months of follow up, in which three main issues were sensation of prolapse, dyspareunia and mean vaginal length. There was no significant statistical difference found in these variables except the mean vaginal length, where measurement showed significantly longer for ASC group than that of SSF group $(\mathrm{p}<0.000005)$.

Table 4: Long term (after 12 months) variables at follow-up visit.

\begin{tabular}{|llll|}
\hline Variables & $\begin{array}{l}\text { SSF, } \\
(\mathbf{n}=\mathbf{1 6}) \\
(\%)\end{array}$ & $\begin{array}{l}\text { ASC, } \\
(\mathbf{n}=\mathbf{1 5}) \\
(\%)\end{array}$ & P value \\
\hline $\begin{array}{l}\text { No } \\
\text { complaints }\end{array}$ & $8(50)$ & $11(73.33)$ & 0.281 \\
\hline $\begin{array}{l}\text { Sensation of } \\
\text { prolapse }\end{array}$ & $2(12.5)$ & $1(6.66)$ & 0.317 \\
\hline $\begin{array}{l}\text { Urinary } \\
\text { symptoms }\end{array}$ & $1(6.25)$ & $1(6.66)$ & 0.7892 \\
\hline $\begin{array}{l}\text { Bowel } \\
\text { symptoms } \\
\text { Dyspareunia }\end{array}$ & $2(12.5)$ & $1(6.66)$ & 0.301 \\
\hline $\begin{array}{l}\text { Mean } \\
\text { vaginal } \\
\text { length }(\mathbf{c m})\end{array}$ & $5.2 \pm 0.833$ & $1(6.66)$ & 0.4361 \\
\hline
\end{tabular}

\section{DISCUSSION}

Although several surgical procedures have been described, randomized controlled studies specifically addressing post-hysterectomy vaginal vault prolapse are limited and most reports are based on case series; complications and recurrences are often described in short term follow up but the effect on bladder, bowel and sexual function is seldom addressed. Long term follow up data related with quality of life are infrequent and there are no established criteria which may help to select the exact procedure for individual woman. Therefore, choice of operation has often based on surgeon's own experience and personal preference. Awareness that POP may be a chronic condition and has multifactorial contribution can assist patient's understanding; this perception may ultimately enhance shared decision making during surgical counseling and acknowledge appropriate patient's expectations in order to minimize negative consequences after surgery. The risk of prolapse repair after hysterectomy was 4.7 times higher in women whose initial hysterectomy was indicated for pelvic organ prolapse and 8 times higher if preoperative prolapse grade 2 or more was present. ${ }^{7}$

Due to lack of standardized definitions for surgical success following pelvic organ prolapse repair, it resulted in highly variable estimates of success. Barber et al opined, success after POP surgery included subjective criteria as absence of bulge symptoms in addition to anatomic criteria (hymen as a threshold for anatomic success) and no need for resurgery. ${ }^{8}$ Several retrospective and prospective studies showed that SSF in case of vaginal vault prolapse is a safe and effective treatment. ${ }^{9,10}$

In various previous studies, it has shown that both the techniques are excellent though each has certain merits and demerits. ASC is an effective option for the correction of advanced POP; its major advantages are excellent ten-year success rates and provide longest possible vaginal length for sexually active women. ${ }^{11}$ As ASC creates more straightway and long vaginal canal compare to exaggerated retroversion of vagina with less physiological axis associated with sacrospinous fixation, it is more suitable for sexually active women. ${ }^{12,13}$ In our study, total vaginal length after one year postoperative follow up in ASC group was $6.95 \pm 0.89 \mathrm{~cm}$ compared to $5.2 \pm 0.833 \mathrm{~cm}$ in SSF group and it is statistically significant $(p<0.000005)$. Despite all these clinical benefits, ASC involves a longer operative time and more hemorrhage, wound infection and gastrointestinal complications than SSF which has also shown in our current study $(\mathrm{p}<0.05)$. Furthermore, it is occasionally associated with synthetic mesh erosion and higher cost though in our study we didn't find any complication related with synthetic mesh. ${ }^{14,15}$

Vaginal sacrospinous fixation is more suitable for physically frail women, because of morbidity associated with abdominal surgery. ${ }^{16}$ Abeera et al concluded that SSF is a patient friendly operative procedure due to shorter duration of operation, quicker recovery in terms of fewer complications and lesser hospital bed occupancy with equal efficacy compare to ASC. ${ }^{17}$ Our study clearly reveals the lower short-term morbidity of vaginal surgery compared to its counterpart (Table 3 ). In the study by Whiteside et al these advantages had out weighed the risk of prolapse recurrence. ${ }^{18}$ Occasionally, damage to the sciatic or pudendal nerve complex is also a risk during SSF procedure. In our limited study, no such mishap had occurred which proved that with proper technique and precautions these can largely be avoided.

Various systemic review and meta-analysis shows that ASC has better anatomical results and lower recurrence at follow up. Sacrocolpopexy strongly holds the vaginal apex with mesh secured to the anterior longitudinal ligament of sacral bone may account for lower rate of recurrences as compared to SSF. ${ }^{19}$ Benson and colleagues randomized patients with prolapse to ASC versus bilateral sacrospinous ligament suspension. ${ }^{20}$ They found superior results with abdominal sacral colpopexy. The reoperation rate was $33 \%$ in the vaginal group and $16 \%$ in the abdominal group. The time of operation was longer for the abdominal group; optimal results were obtained in only $29 \%$ of the vaginal group and $58 \%$ of the abdominal group.

In various published literature, the average follow up after vault prolapse operation ranges from 13.8 months to 4.8 years. Benson et al and Maher et al followed up cases for 1 year which was similar to our study though as per literature review, recurrences usually happened within 6 months of post-operation. ${ }^{19,21-24}$ 


\section{Limitations}

For repair of vault prolapse, the ultimate choice of surgical technique has yet to be settled. It has to be remembered that it can be burdensome to make comparisons between our study data with other studies as there may be differences in patient classification, precise criteria of failure and cure, optimal operating technique as well as skill of the surgery. In most of the previous studies, sample size and follow up were not adequate. So, a larger scale meta-analysis with a longer follow up being necessary to draw a conclusion for optimal surgical technique according to patient's symptoms and signs for better results with higher anatomical efficacy.

\section{CONCLUSION}

The ultimate aim of surgery is to improve the quality of life. All aspects of the prolapse pathology, patient's lifestyle, age, sexual function and presence of co morbidities must be taken in to account. It is also important for the surgeon to understand patient's expectation, exchange opinions regarding available surgical options including drawbacks, so that the appropriate procedure potential to fulfill her expectations can be achieved. ASC and SSF both are valid surgical procedure though Cochrane review showed ASC is associated with lower rate of recurrence vault prolapse and dyspareunia than the vaginal SSF group. These benefits must be balanced against longer operating time, longer time to return to normal activities and increased cost of abdominal approach. The use of mesh or grafts inlays at the time of anterior vaginal repair will reduce the risk of recurrent cystocele. A larger sample and adequately powered randomized controlled trials are needed for further evaluation.

\section{Funding: No funding sources}

Conflict of interest: None declared

Ethical approval: The study was approved by the Institutional Ethics Committee

\section{REFERENCES}

1. Abrams P, Cardozo L, Fall M. The standardization of terminology of lower urinary tract function: report from the standardization sub-committee of the international continence society. Neurol Urodynamics. 2002;21(42):167-78.

2. Bump RC, Maltiasson A, Bo K, Brubaker IP, Delancy $\mathrm{JO}$, Klarskov $\mathrm{P}$ et al. The standardization of terminology of female pelvic organ prolapse and pelvic floor dysfunction. Am J Obstet Gynecol. 1996;175:10-7.

3. Sederl J. Zur operation des prolapses der blind endigenden shiden', Geburtshilfe Frauenheilkd. 1958;18:824-8.

4. Olsen AL, Smith VJ, Bergstrom JO. Epidemiology of surgically managed pelvic organ prolapse and urinary incontinence. Obstet Gynecol. 1997;89(4):501-6.
5. Flynn BJ, Webster GD. Surgical management of apical vaginal defect. Curr Opinion Urol. 2002;12(4):353-8.

6. Toozs-Hobson P, Books K, Cardozo L. Management of vaginal vault prolapse. $\mathrm{Br} \mathrm{J}$ Obstet Gynecol. 1998;105(10):1127-8.

7. Dalleybach P, Kaelin-Gambirasiol, Dubuisson JB. Risk factors for pelvic organ prolapse repair after hysterectomy. Obstet Gynecol. 2007;110(3):625-32.

8. Barbar MD, Brubaker L, Nygaard I. Defining success after surgery for pelvic organ prolapse. Obstet Gynecol. 2009;114(3):600-9.

9. Morgan DM, Rogers MA, Huebner M. Heterogeneity in anatomic outcome of sacrospinous ligament fixation for prolapse: a systemic review. Obstet Gynecol. 2007;109(6):1424-33.

10. Dietz DM, Huisman M, De Jong J. Functional outcome after sacrospinous hysteropexy for uterine descensus. Int Urogynecol J Pelvic floor Dusfunct. 2008;19(6):747-52.

11. Reddy K, Malik TG. Short-term and long-term follow-up of abdominal sacrocolpopexy for vaginal vault prolapse: initial experience in a district general hospital. J Obstet g-Gynecol. 2002;22(5):532-6.

12. Sze EH, Meranus J, Kohli N, Miklos JR, Karram MM. Vaginal configuration on MRI after abdominal sacrocolpopexy and sacrospinous ligament suspension. Int Urogynecol J Pelv Floor Dysfunction. 2001;12:375-9.

13. Rane A, Lim YN, Withey G, Muller R. Magnetic Resonance imaging findings following three different vaginal vault prolapserepair procedures: a randomized controlled study. Aust NZ J Obstet Gynecol. 2004;44:135-9.

14. Wu JM, Wells EC, Hundley AF, Connolly A, Williams KS, Visco AG. Mesh erosion in abdominal sacral colpopexy with and without concomitant hysterectomy. Am J Obstet Gynecol. 2006;194(5):1418-22.

15. Stepanian AA, Miklos JR, Moore RD, Mattox TF. Risk of mesh extrusion and other mesh-related complications after laparoscopic sacral colpopexy with or without concurrent laparoscopic assisted vaginal hysterectomy: experience of 402 patients. J Minim Invesive Gynecol. 2008;15(2):188-96.

16. Addition WA, Livengood CH, Sutton GP, Parker RT. Abdominal sacral colpopexy with mersilene mesh in the retroperitoneal 140-6. position in the management of post-hysterectomy vault prolapse and enterocele. Am J Obstet Gynecol. 1985; 153:

17. Abeera C, Shukr I, Choudhry H. abdominal sacrocolpopexy vs vaginal sacrospinous ligament fixation for vaginal vault prolapse. Pakistan Armed Forces Med J. 2009;5.

18. Whiteside JL, Weber AM, Meyen LA, Walter MD. Risk factors for prolapse recurrence after vaginal repair. Am J Obstet Gynecol. 2004;191:1533-8.

19. Zhang W, Cheon WC, Zhang Li, Wang X, Wei Y. Comparison of the effectiveness of sacrospinous 
ligament fixation and sacrocolpopexy: a metaanalysis. Int Urogynecol J. 2021;1-11.

20. Benson JT, Leucente V, McClellan E. Vaginal versus abdominal reconstructive surgery for the treatment of pelvic support defects: a prospective randomized study with long term evaluation. Am J Obstet Gynecol. 1996;175(6):1418-21.

21. Maher CF, Qatawneh AM, Dwyer PL. Abdominal sacrocolpopexy or vaginal sacrospinous colpopexy for vaginal vault prolapse: a prospective randomized study. Am J Obstet Gynecol. 2004;190(1):20-6.

22. Lantzsch T, Goepel C, Wolters M. Sacrospinous ligament fixation for vaginal vault prolapse. Arch Gynecol Obstet. 2001;265(1):21-5.
23. David-Montefiore E, Barranjar E, Dubernard G. Functional results and quality of life after bilateral sacrospinous ligament fixation forgenital prolapse. Eur J Obstet Gynecol Reprod Biol. 2007;132(2):20913.

24. Assem AM Elbiaa, Magda Kmeikh, AE Omu, Mohamed M Faeghali. A prospective randomized study comparing abdominal sacrocolpopexy and vaginal sacrospinous fixation for the management of vault prolapse. Obstetr Gynecol Int J. 2015;2(1):22-6.

Cite this article as: Dash KK, Dasgupta A, Pal A, Chakraborty A, Dash B, Ghosh P. Comparison of transvaginal sacrospinous ligament fixation with abdominal sacrocolpopexy in treatment of posthysterectomy vault prolapse-a prospective randomized study. Int J Reprod Contracept Obstet Gynecol 2022;11:177-82. 